\title{
Variability in Chromium Segregation at Lath Boundaries in Proton-Irradiated 9 wt.\% Cr Model Steel Determined by Quantitative X-Ray Mapping
}

\author{
K.G. Field,* J. Bentley,** and T.R. Allen* \\ * University of Wisconsin - Madison: Materials Science Program, 1500 Engineering Drive, \\ Madison, WI 53706 \\ ** Oak Ridge National Laboratory: Materials Science \& Technology Division, PO Box 2008, Oak \\ Ridge, TN 37831-6064
}

Ferritic-martensitic $(\mathrm{F} / \mathrm{M})$ steels are under consideration as structural materials for advanced nuclear reactors. F/M steels are preferred for advanced reactor designs over current austenitic stainless steels due to their superior resistance to swelling while maintaining excellent thermal properties [1]. One matter of concern is that radiation-induced segregation (RIS) may occur at grain boundaries. Segregation of $\mathrm{Cr}$ at grain boundaries, either alone or by initiating the nucleation and growth of embrittling precipitate phases, can impact the mechanical properties of the steel. Previous work on F/M steels presents no conclusive trends in the RIS behavior at grain boundaries [2]. It is proposed that a major reason for the apparent inconsistency in RIS behavior is variability in the presence of precipitates, grain boundary orientation and defects from boundary to boundary. These microstructural variations at boundaries may lead to differences in microchemisty among boundaries in F/M steels. In this investigation, quantitative compositions extracted from energy-dispersive Xray spectroscopy (EDS) spectrum images are used to provide insight on how variations in local microstructure affects microchemistry at lath boundaries in irradiated F/M steels.

The steel used in this work is a $9 \mathrm{wt} . \% \mathrm{Cr}$ model alloy designed to approximate the microstructure of commercially available steels but having a simplified chemistry. The composition of the steel is 0.015 wt.\% O, 0.72 wt.\% C, 8.68 wt.\% Cr, balance Fe. Sample coupons were irradiated up to 3 displacements per atom (dpa) using $2.0 \mathrm{MeV}$ protons at $400^{\circ} \mathrm{C}$. Disk samples were extracted from irradiated coupons and prepared using standard dimpling, electro-polishing and ion-milling techniques. With the use of a Philips CM200-FEG operated in scanning transmission electron microscopy (STEM) mode and equipped with an EDAX EDS detector and Emispec Vision system, drift-corrected spectrum images of $32 \times 641.5-\mathrm{nm}$ pixels were acquired with an incident probe size of $\sim 1.5 \mathrm{~nm}$ full width at half-maximum (FWHM) and a dwell time of $1 \mathrm{~s} /$ pixel. Quantitative Fe and $\mathrm{Cr}$ contents were generated using the Cliff-Lorimer method with experimentally determined ' $\mathrm{k}$ ' factors [3].

Four lath boundaries were investigated per irradiation condition. Only one lath boundary in material irradiated to 1 dpa showed $\mathrm{Cr}$ depletion at the boundary, as seen in Fig. 1. All other boundaries in the $1 \mathrm{dpa}$ condition showed no segregation of $\mathrm{Cr}$ at the boundary. All lath boundaries in material irradiated to 3 dpa showed slight enrichment of Cr. Fig. 2 shows the composition enrichment profiles which were extracted from spectrum images by binning data over 5 pixels parallel to the boundary for the material irradiated to $3 \mathrm{dpa}$. For the limited number of lath boundaries investigated in the model steel, it was found the enrichment of $\mathrm{Cr}$ at the lath boundaries increases with increasing dose at $400^{\circ} \mathrm{C}$.

Quantitative EDS mapping allows for a direct coupling between diffraction contrast images and distribution of $\mathrm{Cr}$ in the sample. This provides insight on how changes along and around the grain boundary affect the $\mathrm{Cr}$ segregation at the boundary. It was found that $\mathrm{Cr}$-rich carbides on lath boundaries altered segregation behavior in the $1 \mathrm{dpa}$ condition but not in the $3 \mathrm{dpa}$ condition, but due to the low number of lath boundaries that were characterized it is difficult to determine any conclusive trends. Results for each irradiation condition also suggest minor variability in the $\mathrm{Cr}$ segregation response between lath boundaries with similar microstructure as observed in annular dark field (ADF) images. From the observations, it appears that not only $\mathrm{Cr}$-rich carbides but also 
grain boundary crystallography (misorientation and habit plane) must be key factors driving the varying responses observed at lath boundaries. Composition mapping by STEM-EDS spectrum imaging provides greater insight than one-dimensional profiles on the link between microstructure and microchemistry in irradiated $\mathrm{F} / \mathrm{M}$ steels but with additional analysis of grain boundary orientation an even more complete understanding of RIS responses in F/M steels is expected [4].

\section{References}

[1] R.L. Klueh and D.R. Harries, High-Chromium Ferritic and Martensitic Steels for Nuclear Applications, ASTM, PA, 2001

[2] K.L. Wong et al., J. Nuc. Mater. 386-388 (2009) 227

[3] D.B. Williams and C. B. Carter, Transmission Electron Microscopy, Springer, NY, 1996

[4] Research at the University of Wisconsin was supported by the DOE NE NERI program under project number 08-055 and electron microscopy at the ORNL SHaRE User Facility by the Scientific User Facilities Division, Offices of Basic Energy Science, U.S. Department of Energy.
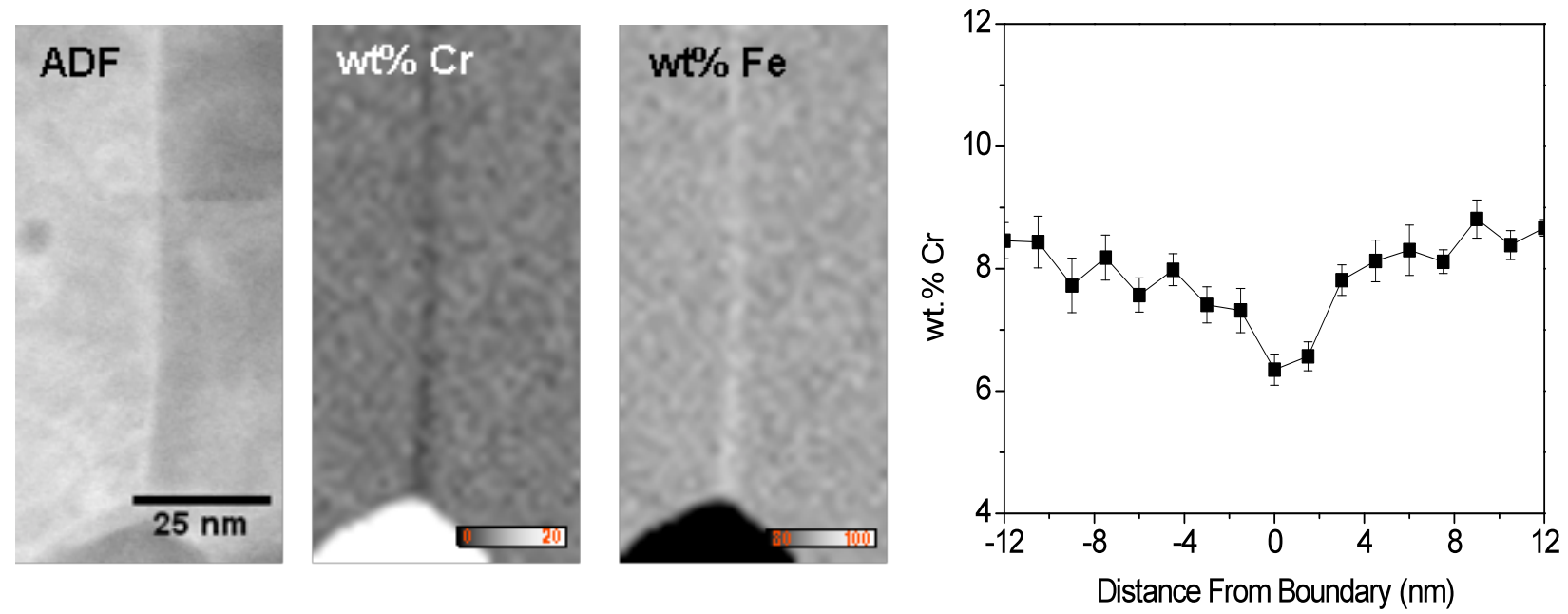

FIG. 1. ADF image of a lath boundary $\left(1 \mathrm{dpa}, 400^{\circ} \mathrm{C}\right)$ with corresponding wt.\% $\mathrm{Cr}$ and Fe maps. Plot shows line profile extracted from $\mathrm{Cr}$ concentration map averaged over 5 pixels parallel to boundary.

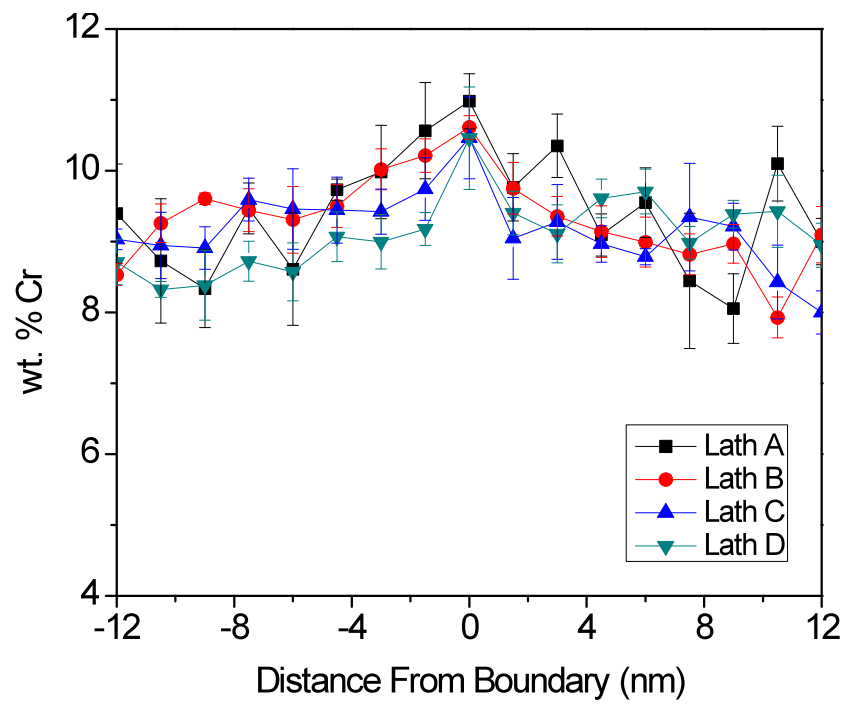

FIG 2. Extracted $\mathrm{Cr}$ line profiles (averaged over 5 pixels parallel to boundary) across lath boundaries in material irradiated to $3 \mathrm{dpa}$ at $400^{\circ} \mathrm{C}$. Plot shows $\mathrm{Cr}$ enrichment at all lath boundaries. 